Available online on 15.05.2018 at http://jddtonline.info
Journal of Drug Delivery and Therapeutics
Open Access to Pharmaceutical and Medical Research
$\begin{gathered}\text { ( 2011-18, publisher and licensee JDDT, This is an Open Access article which permits unrestricted non- } \\ \text { commercial use, provided the original work is properly cited }\end{gathered}$

Open $\odot$ Access

Review Article

\title{
A COMPREHENSIVE STUDY ON EBOLA (EBOV) VIRUS: A THREAT TO HUMAN EXISTENCE
}

\author{
Taneja Mani $^{1 *}$, Malik Anu ${ }^{2}$, Singh Manisha ${ }^{1}$, Das Doli ${ }^{1}$ \\ ${ }^{1}$ Assistant Professor, Gurugram Global College of Pharmacy, Farrukhnagar, Gurugram, Haryana, India-122506 \\ ${ }^{2}$ Assistant Professor, RP Institute of Information and Technology, Bastara, Karnal, Haryana, India
}

\section{ABSTRACT}

Ebola hemorrhagic disease is a severe, an acute, often fatal disease in humans and non-humans which is caused by infection with a virus of family: Filoviridae, genus: Ebola virus. The incubation period of ebola virus disease (EVD) varies from 2-21 days, with an observed average of 8 to 10 days by following introduction of Ebola virus in the human population through animal-to-human transmission, person-to-person transmission by direct contact body fluids/secretions of infected persons. The most common symptoms include sudden onset of fever, intense weakness, muscle pain, headache and sore throat, vomiting, diarrhea, rash, impaired kidney and liver function, and at advanced stage both internal and external bleeding. The virus is transmitted by contact with body fluids of infected humans or an animal is primarily responsible for the virus outbreak. Fruit bats are considered as the natural reservoirs of the virus. The most general assays used for antibody detection are direct IgG and IgM ELISAs and IgM capture ELISA. An IgM or rising IgG titer (four-fold) contributes to strong presumptive diagnosis. Currently neither a licensed vaccine nor an approved treatment is available for human use. In this review, the Ebola virus: life cycle and pathogenicity in humans, diagnosis, pharmacotherapy and their prevention is summarized.

Keywords: Filoviridae, Ebola, Outbreak, Transmission, Symptoms, Hemorrhagic fever.

Article Info: Received 20 Jan, 2018; Review Completed 31 March 2018; Accepted 01 April 2018; Available online 15 May 2018

\section{Cite this article as:}

Taneja M, Malik A, Singh M, Das D, A comprehensive study on Ebola (Ebov) virus: a threat to human existence, Journal of Drug Delivery and Therapeutics. 2018; 8(3):124-132 DOI: http://dx.doi.org/10.22270/jddt.v8i3.1688

*Address for Correspondence:

Mani Taneja, Assistant Professor, Gurugram Global College of Pharmacy, Farrukhnagar, Gurugram, Haryana, India-122506

\section{INTRODUCTION}

Ebola, previously known as Ebola hemorrhagic disease, is a severe, an acute, often fatal disease in humans and non-humans. It is a rare and deadly disease caused by infection with a virus of family: Filoviridae, genus: Ebola virus. There are five identified ebola virus species, four of which have caused disease in humans known as Ebola Virus Diseases (EVD) ${ }^{\mathbf{1 , 2}}$. Ebola virus has caused the majority of human deaths from EVD, and is the cause of the 2013-2014 ebola virus epidemics in West Africa, which has resulted in at least 20,834 suspected causes and 8,251 confirmed deaths ${ }^{1}$. There are no licensed specific treatments or vaccine available for use in peoples and animals.
There are five identified ebola virus species which differ in their virulence for humans i.e. Zaire ebola virus; Sudan ebola virus; Tai Forest ebola virus (Cote d'Ivoire Ebola virus); Bundibugyo ebola virus caused disease in humans and the fifth Reston ebola virus has caused disease in nonhuman primates (such as Monkeys, gorillas and chimpanzees) but not in humans ${ }^{1,2}$.

The incubation period of ebola virus disease (EVD) varies from 2-21 days, with an observed average of 8 to 10 days. Following the introduction of Ebola virus in the human population through animal-to-human transmission, person-to-person transmission by direct contact body fluids/secretions of infected persons is considered the principal mode of transmission. Indirect contact with environment and families soiled with contaminated body fluids (e.g needles) may also occur. 
Airborne transmission has not been documented during previous EVD outbreaks. There is no risk of transmission during the incubation period.

The most common symptoms experienced by persons infected with the virus are the sudden onset of fever, intense weakness, muscle pain, headache and sore throat. This is the followed by vomiting, diarrhea, rash, impaired kidney and liver function, and at advanced stage both internal and external bleeding. Laboratory findings include low white blood cells and platelet counts and elevated liver enzymes ${ }^{5}$.

\section{EPIDEMIOLOGY}

The filo viruses were first recognized in 1967, when the inadvertent importation of infected monkeys from Uganda into Germany and Yugoslavia resulted in explosive outbreak of severe illness among vaccine plant workers who came into direct contact with animals by killing them, removing their kidneys, or preparing primary cell cultures for polio vaccine production ${ }^{6}$.

EVD first appeared in 1976 in two simultaneous outbreaks, one in Nzara, Sudan and other in Yambuku, Democratic republic of Congo. The latter occurred in a village near the Ebola River, from which the disease takes its name ${ }^{1}$.

Ebola virus was first discovered in 1976. There have been more cases and deaths in the outbreak than all others combined. It has also spread between countries starting in guinea then spreading across land borders to Sierra Leone and Liberia, by air(one traveller only) to Nigeria, and by land (one traveler) to Senegal ${ }^{\mathbf{1}}$.

2014 outbreak in West Africa- By far, the largest outbreak of Ebola virus disease ever recorded is currently occurring in West Africa with the Zaire species of the virus ${ }^{6-13}$. Although most previous Ebola outbreaks occurred in central Africa, this outbreak started in the West Africans nation of Guinea in late 2013 and was confirmed by the World health organization (WHO) in March 2014, $4^{\mathbf{7} 14}$. The initial case was a 2 year old child in Guinea, who developed fever, vomiting, and black stools, without other evidence of hemorrhage ${ }^{5}$. The outbreak subsequently spread to Liberia, sierra Leone, Nigeria, Senegal and Mali ${ }^{15-17}$. Sequence analysis of viruses isolated from patients in Sierra Leone indicates that the epidemic has resulted from sustained person-to-person transmission, without additional introductions from animal reservoirs ${ }^{18}$. The case -fatality rate has been estimated to be approximately 70 percent $^{19}$.

As of October 19, 2014, the cumulative number of portable, suspected, and laboratory -confirmed cases attributed to Ebola virus is 9936, including 4877 deaths ${ }^{20}$. These include 443 health care workers, of whom approximately 55 percent have died. However, Nigeria and Senegal have not reported any new cases since September 5, 2014, and respectively ${ }^{\mathbf{2 0 - 2 3}}$.

Cases of Ebola virus disease related to this outbreak have also been reported outside of West Africa. On September 30, 2014, the first travel-associated case of Ebola was reported in the United States ${ }^{24}$. An individual who traveled from Liberia to Dallas, Texas first developed clinical findings consistent with ebola virus disease approximately five days after arriving in the United States. The patient was asymptomatic prior to and during the flight. Two health care workers involved in the care subsequently developed ebola virus disease ${ }^{25}$. So, it was concluded to say that person to person transmission was for this disorder.

\section{4 outbreak in the democratic republic of Congo-} In august of 2014, an outbreak of Ebola virus disease was reported in the democratic republic of Congo ${ }^{26,27}$. The index case was a pregnant woman who prepared bush meat from an animal that had been killed by her husband. As of October 20, 2014, a total of 66 cases of EVD (confirmed and probable), including 49 deaths, have been connected to this outbreak ${ }^{\mathbf{2 0}}$.

Outbreak in India: India which had so far remained unscathed from the virus, has diagnosed a fresh case of it after an Indian, semen sample showed traces of ebola virus. The man, a 26 year old Indian, working in Liberia, was earlier treated and cured of the deadly virus, is kept in isolation at delhi's airport health organization quarantine centre ${ }^{28,29}$.

\subsection{Virus Reservoir}

The natural reservoir host of Ebola has not yet been identified; the manner by which the virus first appears in a human at the start of an outbreak is unknown. Perhaps the greatest mysteries regarding the filoviruses are the identity of their natural reservoir and the mode of transmission from the reservoir to wild apes and humans. When an infection does not occur in humans, there are several ways the virus can be spread to others 5,30

\section{TRANSMISSION}

Experiments in laboratory animals indicate that filoviruses can initiate infection via many routes, including ingestion, inhalation, or passage through breaks in the $\operatorname{skin}^{31}$. Non human's primates can be infected with Ebola or Marburg virus through droplet inoculation of virus into the mouth or eyes, suggesting that cases of human infection result from the inadvertent of virus to these sites from the patient's own contaminated hands ${ }^{32,33}$.

3.1. Person to person- Person to person transmission occurs through direct contact of broken skin or unprotected mucous membranes with virus-containing body fluids like blood feces and vomit from which the developed signs and symptoms of illness ${ }^{34}$. The viruses that cause Ebola are often spread among families and friends, because they come in close contact with blood or body fluids when caring for ill person. It has been also detected in urine, semen and breast milk. Saliva and tears also harbor the virus. Thus, contact with any of these fluids can pose potential risk. During the outbreak of Ebola, the disease can spread quickly with in healthcare settings, such as clinics or hospitals ${ }^{10}$.

3.2. Direct contact with the objects (like needles and syringes) that have been contaminated with the blood or 
body fluids of an infected person or with infected animals.

Ebola virus may also be transmitted though contact with previously contaminated surfaces and objects. Limited data suggest that viable virus may exist for upto several days on fomities. Although there are no high- quality data to confirm transmission through this type of exposure, the potential risk can be reduced by proper environmental learning ${ }^{2}$.

\section{INCUBATION PERIODS}

patients with EVD typically have an abrupt of symptoms 8-12 days after exposure (range 2 to 21 days $)^{35,36}$. However, all symptomatic individuals should be assumed to have high levels of virus in the blood and other body fluids and appropriate safety precaution should be taken ${ }^{37}$.

\section{SYMPTOMS AND SIGNS}

the most common sign and symptoms reported from west Africa during the 2014 outbreak include: fever (85 percent), fatigue (76 percent), vomiting (68 percent), diarrhea (66 percent) and loss of appetite $(65 \text { percent })^{35}$.

Important clinical findings of patients with Ebola and Marberg virus disease are as follows:

- Nonspecific flu-like symptoms- Ebola and Marberg hemorrhagic fever typically begin with the abrupt onset of fever, chills and general malaise. Other signs and symptoms include weakness, anorexia, severe headache, and pain in the muscles of the trunk and lower back ${ }^{\mathbf{3 8}}$. Multisystem involvement follows that includes prostration; nausea, vomiting, abdominal pain, diarrhea and pancreatitis; chest pain, cough, and pharyngitis; vascular and neurological manifestations.

- Rash- some patients develop a diffuse eruthematous, nonpruritic maculopapular rash by day five to seven of illness. The rash usually involves the face, neck, trunk, and arms, and can desquamate in servivors ${ }^{38-}$ 42,4

- Gastrointestinal- gastrointestinal signs and symptoms usually develop several days after the initial presentation. These include watery diarrhea, nausea, vomiting, and abdominal pain.

- Hemorrhage- bleeding is often not observed in the early phase of illness, but may manifest later in the course of disease as petechiae, ecchymosis/bruising, oozing from vein puncture sites, or mucosal hemorrhage. During the outbreak in West Africa, approximately 20 percent of patients have unexplained bleeding, which is the most commonly manifested as blood in the stool (about 6 percent) ${ }^{35}$.

- Other findings- patients with Ebola virus disease can persist with addition findings such as hiccups, chest pain, shortness of breath, headache, confusion, seizures, and cerebral edema. Liver failure, multiorgan dysfunction, conjunctival infection and dark red discoloration of the soft palate are other common physical findings 4 .

In non-fatal cases, patients typically improve approximately 6 days after the onset of symptoms. The formation of antigen-antibody complexes during recovery may cause acute arthralgias and other symptoms. Fatal disease has been characterized by more severe clinical signs early during infection and progression to multi-organ failure and septic shock. Death typically occur between days six and sixteen $16^{31}$.

Ebola virus: life cycle and pathogenicity in humans:-

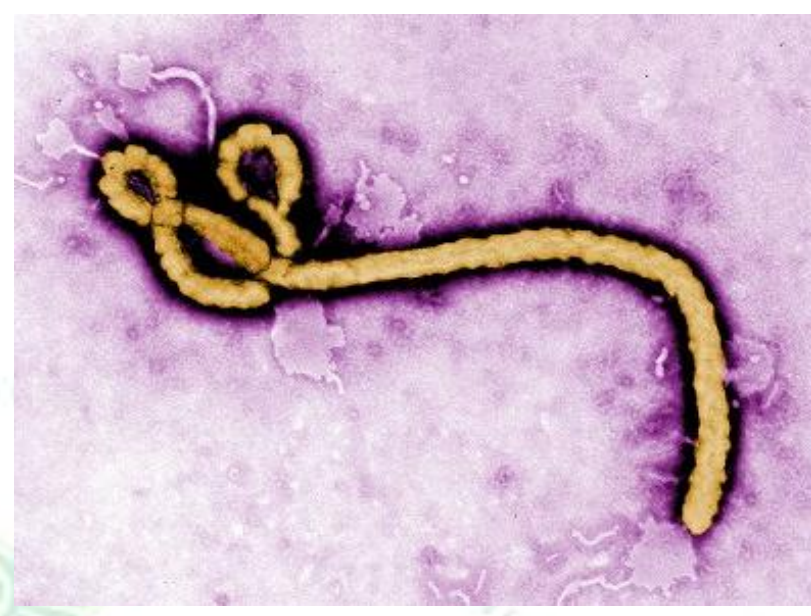

The much-talked about Ebola virus is an encapsulated single-stranded (ss) negative RNA virus belonging to the family Filoviridae.

\section{Cell and Molecular Biology:}

Electron microscopy studies show that the Ebola virus has a filamentous appearance typically $800 \mathrm{~nm}$ long and $80 \mathrm{~nm}$ in diameter. Each viral particle or virion consists of a nucleocapsid consisting of the negative ssRNA genome surrounded by the nucleoprotein NP, the polymerase cofactor VP35, the virus specific transcription activator VP30, and the viral RNA polymerase L protein (fig 1). This nucleocapsid is encapsulated by an outer viral envelope originating from the host cell membrane with characteristic $10 \mathrm{~nm}$ long viral glycoprotein (GP) spikes. The matrix between the outer viral envelope and the nuclecapsid is occupied by the VP40 and VP24 viral proteins ${ }^{\mathbf{4 3}}$.

In green is the nucleocapsid made of the ssRNA genome and the proteins NP (large green spheres), VP35 (in purple), VP30 (in blue) and L (in grey) proteins. Note that the NP or N, VP35 and L proteins are shown outside the virion for better visibility. The nucleocapsid is surrounded by the outer membrane derived from host cell membrane (in light blue) and is studded with viral GP spikes (yellow studs). The matrix between the nucleocapsid and the outer membrane (in brown) comprises of the VP40 (brown) and VP24 (orange) proteins. Source: Viral Zone (ExPASy). 


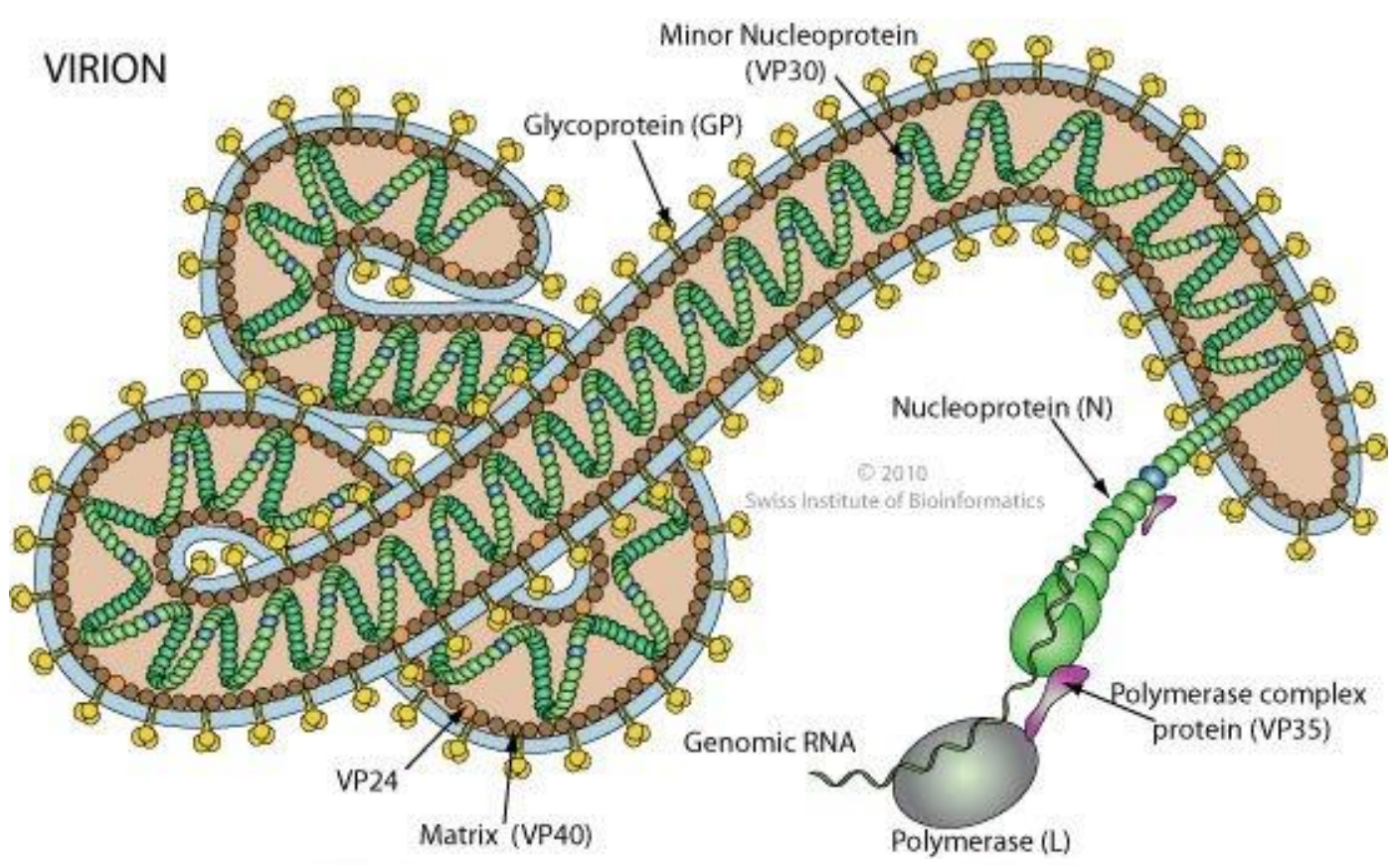

Figure 1: Schematic representation of the Ebola virus.

The virus genome is $19 \mathrm{~kb}$ (kilobases) in length, and encodes seven structural and one non-structural protein. The fig below shows the virus genome with the gene order.

$(-)$ strand RNA genome

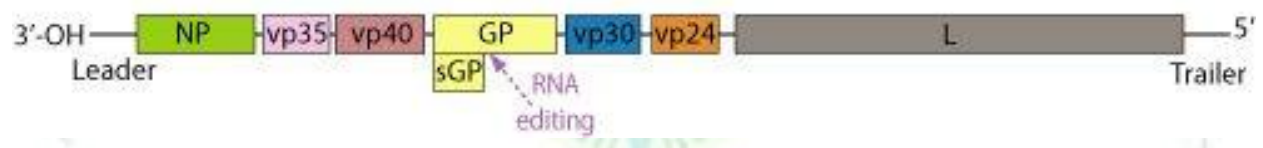

Figure 2: Diagrammatic representation of the Ebola virus genome.

The leader and the trailor regions are untranscribed sequences which regulate transcription, replication and packaging of genomes into new virions.

The viral RNA polymerase binds at the leader end to initiate sequential transcriptional of each gene. The newly transcribed mRNAs are capped and polyadenylated by the $\mathrm{L}$ protein during this process. Of note, the primary mRNA transcribed from the GP gene encodes a small, non structural, soluble protein called sGP which is secreated from the infected host cells into blood. The fully functional glyprotein is a result of RNA editing and this protein is expressed on the cell surface as GP spikes ${ }^{44}$. These GP spikes, help in anchorage and membrane fusion of the virion to the host cell, and are a crucial factor for ebola virus pathogenicity.

The matrix protein VP40 is important for maintaining the structural integrity of the virion. It is also associated with endocytosis and virus budding and has the ability to release itself from the cells even in the absence of other viral proteins ${ }^{45}$. The second matrix protein VP24 suppresses interferon production in the host cell ${ }^{\mathbf{4 6}}$. In remaining proteins namely NP, VP35, VP30 and L proteins from the structure components of the nuclecapsid. More, these proteins also catalyse genome transcription and replication ${ }^{47}$.

\section{VIRUS TRANSMISSION}

It is not entirely known how Ebola spreads in humans, but contact with body fluids of infected humans or animals is primarily responsible for the virus outbreak.
Fruit bats are the natural reservoirs of the virus. The US centre for Disease Control has a self-explantory cartoon depicting the likely method of virus transmission from bats to humans. Fig 3.

\section{THE LIFE-CYCLE OF THE VIRUS}

\section{(1) Host immune system attack}

The early targets of the virus are the monocytes and the macrophages of the host immune system and other target cells are liver cells, and endothelial cells. Ebola virus employs different mechanisms to interfere with or even ignore the host immune system completely. Most of these host immune system attack processes involve the virus structural proteins. One such mechanism is called the antibody-dependent enhancement (ADE) wherein the host antibodies (Abs), facilitate or enhance the virus's attachment to the host cells increasing infection in these cells. The Abs bind to antibody receptors at their $\mathrm{Fc}$ sites while the virus binds to the antigen-binding site at the free end of the $\mathrm{Abs}^{48}$. In vitro studies in Ebola showed that the virus activates the classical pathway of the complement system. Initially, the Ebola virus binds to its receptor on the host cell surface. Following this, Abs bind to the glycoprotein (GP) spikes of the virus, and the C1q component of the complement enhances the Ab-GP complex to bind to $\mathrm{C} 1 \mathrm{q}$ ligands on the host cell surface thus increasing the interaction of the host cell surface. This way, the GP spikes on the virus use the host immune system (Abs and the complement components) to enhance its attachment to the target cells ${ }^{49}$. 


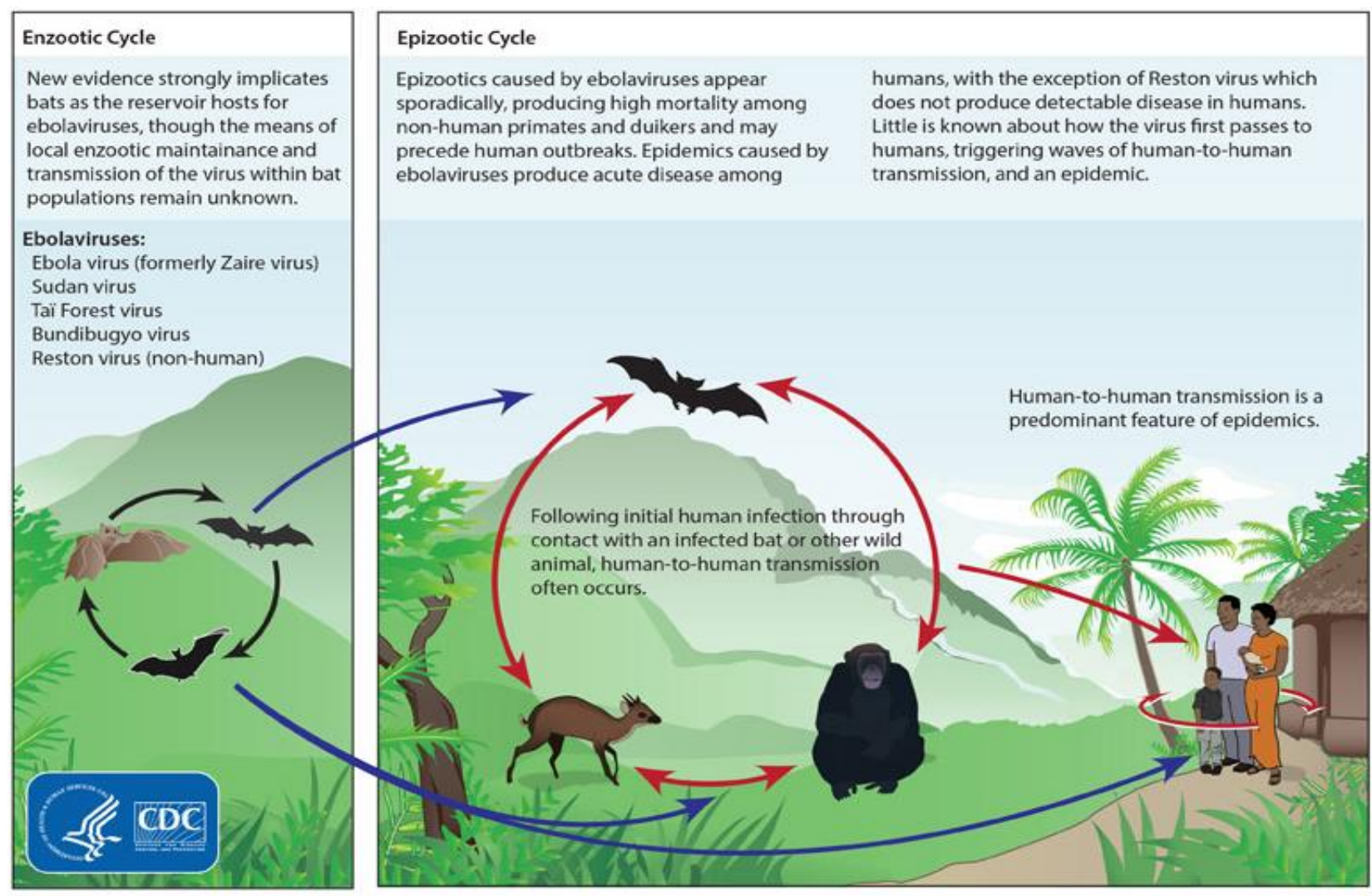

Figure 3: Ebola virus transmission from fruit bats to humans.

The virus is transmitted by contact with contaminated body fluids. Figure 3: Ebola virus transmission from fruit bats to humans.

In addition to ADE, the virus protein VP35, blocks the immune system's interferon (IFN) pathways comprising of various cytokines that exert anti-viral responses.VP35 blocks IFN response by competing with the protein such as retinoic acid -inducible gene 1 (RIG1) protein to activate the IFN pathway ${ }^{50}$. Along with VP35, VP24 also blocks IFN pathway activation. VP24 blocks transcription factors like STAT1 that regulate transcription of the immune system genes4.

As aforementioned, the primary mRNA transcript of the GP gene encodes the soluble sGP which is speculated to have an anti-inflammatory role during infection which further enhances the virus' escape from host immune system response. Moreover, sGP has many similar epitopes with GP, so it could potentially sequester or absorb host Abs to block their downstream action ${ }^{54,55}$. Thus, the viral proteins disrupt different components of the immune system to attach to the host cell for subsequent entry. In this way, it attacks the immune system of the host cell.

\section{(2) Virus entry into the host cell}

The exact mechanism by which the Ebola virus enters host cells remains poorly understood. One general mechanism to infect host cells for most enveloped viruses including the Ebola virus is Endocytosis. Research indicates that the virus utilises a lipiddependent, non-clathrin and dynamin-independent endocytic pathway of entry. Macropinocytosis is the most likely mechanism employed by the Ebola virus ${ }^{\mathbf{5 6}}$. This process involves outward extensions of the plasma membrane formed by actin polymerization, which can fold back upon themselves. The distal loop ends of these extensions or membrane ruffles can fuse to form a macriopinosome. This also means that actin and its associated polymerising proteins play a pivotal role in virus entry. The exact mechanism by which the virus induces macropinocytosis is not understood. It is speculated that interactions between GP and host cell surface receptors can trigger macropinocytosis to initiate viral entry ${ }^{56}$.

\section{(3) Virus replication}

Once inside the host cell, the virus initiates transcription at the leader end of the genome with the binding of the polymerase complex5. VP30 is an important transcription activation factor for viral genome transcription, while VP24 is an inhibitor to this process. The exact mechanism of VP24-dependent transcription termination is not fully understood, but it seems to be important for converting the virus from its transcriptional or replication active form to one that is geared for virion assembly and exit from host cell ${ }^{55}$.

\section{(4) Virus budding and exit from host cell}

Following replication, the cell loses its connection with other cells as well as attachment to its substrate. Meanwhile, the newly synthesized genomes are packaged into new buds or virions and egresses from the host cell surface with the help of the matrix protein VP40. VP40 interacts with ubiquitin ligase Nedd4 which is a part of human ubiquitination enzyme pathway and links multiple copies of ubiquitin molecules to VP40 ${ }^{\mathbf{5 7}}$. VP40 itself is transported to the host cell plasma membrane using the COPII transport system ${ }^{\mathbf{5 5}}$. Once in the plasma membrane, the virus moves through lipid 
rafts where the final assembly and budding of the virions occur, before their final exit from the host cell.

Although the structural components of the virus are known, the exact mechanisms by which it causes disease in humans are not completely understood. This poses a major challenge for treatment and to date prevention is the best mode of action to avoid an Ebola outbreak.

\section{DIAGNOSIS}

It can be difficult to distinguish EVD from other infectious diseases such as malaria, typhoid fever and meningitis because a Confirmation that symptoms are caused by Ebola virus infections are made using the following investigations ${ }^{\text {57-61. }}$ :

\begin{tabular}{|l|l|}
\hline Timeline of infection & Diagnostic tests available \\
\hline Within a few days after symptoms begin & $\begin{array}{l}\text {-antigen capture enzyme-linked immunosorbent assay(ELISA) testing } \\
\text {-igM ELISA } \\
\text {-polymerase chain reaction (PCR) } \\
\\
\text {-virus isolation }\end{array}$ \\
\hline Later in disease course or after recovery & -igM and igG antibodies \\
\hline Retrospectively in deceased patients & -immunohistochemistry testing \\
& -PCR \\
& -Virus isolation \\
\hline
\end{tabular}

\section{Ebola Virus: Development of Vaccines and Therapeutic Drugs ${ }^{62}$}

The 2014 outbreak of Ebola virus highlights the urgent need to develop an effective vaccine to prevent the spread of this deadly virus, and effective therapies to improve survival rates among those infected with EVD. A DNA vaccine candidate should begin clinical trials in humans this year, and investigational drugs in development to treat patients suffering from viral hemorrhagic fever include monoclonal antibodies, siRNA-based therapeutics, and antiviral small molecule $\operatorname{drugs}^{63}$.

Tekmira's siRNA-based investigational drug TKMEbola has been authorized by FDA under expanded access protocols to be administered to patients diagnosed with or suspected to be infected with Ebola ${ }^{\mathbf{6 3}}$.

\section{Recent Research Reports on Ebola $^{63}$ :}

- In April 2014, a group of researchers from the CDC published a study on High-throughput, luciferasebased reverse genetics systems for identifying inhibitors of Margburg and Ebola viruses, using codon-optimized Ebola virus genes synthesized by Genscript.

- A 2013 Molecular therapy paper report pre-clinical results for a DNA vaccine that protects against Ebola and Marburg in guinea pigs and rodents. Inovia Pharmaceuticals is using its SynCon platform to develop synthetic gene-based vaccine against Ebola, $\mathrm{HIV}$, cancer-causing viruses, and influenza.

- London, Jan 06 (IANS) Oxford University doctors and scientists are starting the first safety trial of an experimental preventative Ebola vaccine, aiming to have vaccinated all 72 healthy adult volunteers by the end of January. Volunteers for the trial, aged from 18-50, will be the first humans to receive the vaccine, which is developed by Janseen Pharmaceutical Companies of Johnson and Johnson, Xinhus reported citing a press release from the university issued Tuesday. The study involves a prime-boost vaccine regimen, which does not contain any replicating virus, so it in not possible to be infected with Ebola, according to the researchers. Patients are first given a prime immune system to stimulate an initial immune response, and then a boost intended to further enhance the level of the body's immune response over time ${ }^{64}$.

\section{New Ebola Drugs Cures Monkeys in Clinical Trial ${ }^{62}$}

The cure of the fatal Ebola virus may finally have just been discovered. Recently, there has been reports by scientists of Ebola-infected monkeys being completely cured. The medication, Zmapp, is at present being used to treat patients infected with the virus including William Pooley-a British nurse- who is currently being treated at London-based Royal Free hospital for contacting the disease in Sierra Leone ${ }^{\mathbf{6 2}}$.

Around 18 monkeys infected with Ebola were found to be totally cured after being administered ZMapp. The results, according to experts, were heavily encouraging. The result revealed that these trials now have a strong backing and should be used in humans. On the other hand, it should be noted that two patients treated with the drugs had died, but it may have been because the drug was administered too late for it to be effective ${ }^{\mathbf{6 2}}$.

\section{Ongoing Ebola Drug Development efforts ${ }^{63}$ :}

- Newlink Genetics Crop is poised to begin the first clinical trials of an Ebola vaccine an attenuated live virus, vesicular stomatitis virus (VSV), a common livestock pathogen, into which an Ebola viral coat protein has been introduced ${ }^{\mathbf{6 3}}$.

- A vaccine currently poised to begin clinical trials as soon as 2014 is a DNA vaccine, containing synthetic genes encoded by the Ebola virus delivered in a nonreplicating adenoviral vector. DNA vaccine stimulates a robust immune response to high-level expression of specific antigenic proteins delivered in vector optimized for safety ${ }^{63}$.

- DNA vaccine efficacy can be enhanced through codelivery of synthetic genes encoding adjuvants such as cytokinins, chemokines, or synthetic genes encoding ${ }^{63}$. 
- Researchers at the NIH's Vaccine Research Center (VRC) have designed a DNA vaccine against Ebola in collaboration with Okairos, which was recently acquired by GSK. This vaccine candidate is composed of a non-replicating chimpanzee adenovirus vector vaccine into which two Ebola genes have been inserted. Clinical trials are expected to begin in fall 2014 with approval coming soon as in $2015^{63}$

- Several investigational drugs have received FDA permission to be administered to patients infected with Ebola virus, including the monoclonal antibodies cocktail ZMapp and the RNA based therapeutic TKM Ebola ${ }^{63}$.

- siRNA delivered through lipid nanoparticles: Tekrima is developing the RNAi-based therapeutic TKM. Ebola to combact the Zaire species of ebola virus $(\mathrm{ZEBOV})^{63}$.

\section{Prevention and control}

Contact tracing, a good laboratory service, safe burials and social mobilization ${ }^{1}$. Raising awareness of risk factor among people against EBOLA virus and their preventive measures if you must travel to an area affected by the 2014 EBOLA outbreak, protect yourself by doing the following ${ }^{1}$ :

- Wash hand frequently or use an alcohol-based hand sanitizer.

- Avoid contact with blood and body fluids of any person, particularly someone who is sick.

- Do not touch the one who has died from Ebola.

- Do not touch bats and nonhuman primates or their blood and fluids and do not touch or eat raw meat prepared from these animals.

Other protective measures also are taken by individuals in an effective way to reduce human transmission. Risk reduction messaging should focus on several factors ${ }^{\mathbf{6 5 , 6 6}}$

- Reducing the risk of wildlife-to-human transmission from contact with infected fruit bats and monkeys/apes and the consumption of their raw meat. Animals should be handled with gloves and other appropriate protective clothing. Animal products (blood and meat) should be thoroughly cooked before consumption.
- Reducing the risk of human-to-human transmission with direct or close contact with people with EVD symptoms, particularly with their body fluids. Gloves and appropriate personal protective equipments should be worn when taking care of ill patients at home.

- Outbreaks containment measures including prompt and safe burial of dead, identifying people who may have been contact with someone infected with Ebola, monitoring the health of contacts for 21 days, the importance of separating the healthy from the sick to prevent further spread, the importance of good hygiene and maintaining a clean environment.

- Information for patients- upto date offers two types of patient education materials, "The Basics" and "Beyond the Basics." The Basics patient education pieces are written in plain language, at the $5^{\text {th }}$ to $6^{\text {th }}$ grade reading level, and they answer the four or five key questions patient might have about a given condition. Beyond the Basics patient education pieces are longer, more sophisticated, and more detailed. These articles are written at the $10^{\text {th }}$ to $12^{\text {th }}$ grade reading level and are best for patients who want in-depth information and are comfortable with some medical jargon.

\section{SUMMARY AND CONCLUSION}

Last year 2014 was very drastic for the people who suffered from Ebola virus disease. Our motive to write this review article is only to give the tribute for the patients or persons who died from ebola virus and another is to spread the awareness amongs the peoples for ebola virus by giving their information to the patients and peoples related to their sign and symptoms, diagnose, treatment and precautions for protecting ourself from this disease.

From this article we concluded that the EVD is controlled by either increasing the immune system of the human body by taking Basil leaves and fruits as immunity boosters or by inhibiting the replication of the virus in the host cell by producing Ebola vaccines which is going on research work. More rapidly exiting the virus from the host cell increases the prognosis of the host life is also finding to controlled the EVD.

Currently no vaccine is produced for the EVD but most of the drugs and vaccine are ongoing Ebola Drug Development efforts. If any vaccine or drug will produce, this article will be updated. 


\section{REFERENCES}

1. Ebola response report -situation report-31 December 2014,World Health Organization, Retrieved 1 January 2015,Available at http://apps.who.int/ebola/en/statusoutbreak/situation-reports/ebola-situation-report-31-december$\underline{2014}$

2. Classification of Ebola virus species which differ in their virulence for humans,2018Available at; http://www.who.int/mediacentre/factsheets/fs103/en/

3. WHO Ebola virus disease: background and summary,2017,Available at; http://www.who.int/csr/don/archive/disease/ebola/en/

4. Martini GA, Marburg agent disease: In man, Transactions of The Royal Society of Tropical Medicine and Hygiene, 1969; 63(3):259.

5. Bray M, Richman DD, Whitley RJ, Hayden FG, Filoviridae. In: Clinical Virology,ASM Press, Washington DC 2002, 875 890

6. World Health Organization, Unprecedented number of medical staff infected with ebola.,Available at; http://www.who.int/mediacentre/news/ebola/25-august2014/en/

7. Baize S, Pannetier D, Oestereich L, Emergence of Zaire Ebola virus disease in guinea, New England Journal of Medicine, 2014; 371(15):1418-25

8. World Health Organization,Global Alert and Response, Ebola virus disease,West Africa-update. Available at, https://www.uptodate.com/contents/epidemiology-andpathogenesis-of-ebola-virus-disease

9. Feldmann H, Ebola - a growing threat? New England Journal of Medicine, 2014; 371(15):1375-1378

10. Green A, Ebola emergency meeting establishes new control centre. Lancet, 2014; 384(9945):746.

11. Ansumana R,Bonwitt J, Stenger DA, Jacobsen KH, Ebola in Sierra Leone: a call for action. Lancet 2014; 384(9940):303.

12. Frieden TR, Damon I,Bell BP,et al. Ebola-new challenges, new global response and responsibility. New England Journal of Medicine 2014; 371(13):1177-80

13. Chan M, Ebola virus disease in West Africa - no early end to the outbreak, New England Journal of Medicine(2014); 371(13):1183-85.

14. World Health Organization,Global Alert and Response, Ebola virus disease, available at,http://www.who.int/csr/disease/ebola/manual_EVD/en/

15. World Health Organization, Ebola situation in Senegal remain stable, Available at,

http://www.who.int/mediacentre/news/ebola/12-september2014/en/

16. World Health Organization, Ebola response roadmap situation report,26 September 2014. Available at; http://apps.who.int/iris/bitstream/10665/135029/1/roadmapupd ate26sept14_eng.pdf?ua=1 (Accessed on September 26, 2014).

17. World Health Organization. Mali confirms its first case of Ebola Available at; http://www.who.int/mediacentre/news/ebola/24-october2014/en/(Acessed on October 24, 2014).

18. Gire SK, Goba A, Andersen KG, et al. Genomic surveillance elucidates Ebola virus origin andtransmission during the 2014 outbreak, Science New York 2014; 345(6202):1369-72.

19. WHO Ebola Response Team. Ebola virus disease in West Africa-the first 9 month of the epidemic and forward projections. New England Journal of Medicine, 2014; 371:1481-95

20. World Health Organization, Ebola response roadmap situation report,22 October 2014. Available at; http://apps.who.int/iris/bitstream/10665/137091/1/roadmapsitr ep22oct14_eng.pdf?ua=1(Acessed on October 22, 2014).

21. Centers for Disease Control and Prevention.2014.Ebola outbreak in West Africa. Available at; http://www.cdc.gov/vhf/ebola/outbreaks/2014-westafrica/index.html(Accessed on September 29, 2014).

22. Mirkovic K, Thwing J, Diack PA. Importation and containment of ebola virus disease-Senegal,August-September
(2014), Morbidity and Mortality Weekly Report (MMWR)2014; 63(39):873-74.

23. Shuaib F, Gunnaia R, Musa EO, et al.Ebola virus disease outbreak-Nigeria,(july-september 2014).Morbidity and Mortality Weekly Report 2014; 63(39):867-72.

24. Centers for Disease Control and Prevention. First imported case of Ebola diagnosed in the United States. Available at; https://www.cdc.gov/vhf/ebola/outbreaks/2014-westafrica/united-states-imported-case.html.

25. Centres for Disease Control and Prevention. Cases of Ebola diagnosed in the United States. Available at; http://www.cdc.gov/vhf/ebola/outbreaks/2014-westafrica/united s-state-imported-case.htmlindex.html(Accessed on October 15, 2014).

26. World Health Organization, Global Alert and Response, Ebola virus disease-Democratic Republic of Congo,Available at, https://www.uptodate.com/contents/epidemiology-andpathogenesis-of-ebola-virus-disease

27. Maganga GD, Kapetshi J, Berthet N, et al,Ebola virus disease in the Democratic Republic of Congo, N Engl J Med,2004,371),2083-91.

28. The Ebola virus outbreak in India. Available at; https://www.mapsofindia.com/my-india/society/ebola-virusoutbreak-is-india-prepared

29. Times of india page no. 1 and 8 wed., nov. 19, 2014 inclusive of delhi time/ times of india.com/epaper.timesofindia.com.

30. Chowell G, Nishiura $H$. "Transmission dynamics and control of Ebola virus disease (EVD): a review". BMC Med 2014; 12(1):196. doi: 10.1186/s12916-014-0196-0 . PMC 4207625 .PMID 25300956

31. Mahanty S, Bray M. Pathogenesis of filoviral haemorhhagic fevers,Lancet Infect Dis, 2004; 4(8):487-498.

32. Jaax NK, Davis KJ, Geisbert TJ, Lethal experimental infection or rhesus monkeys with Ebola-Zaire(Mayinga) virus by the oral and conjunctival route of exposure, Arch pathol Lab Med, 1996; 120(2):140-55.

33. Schou $\mathrm{S}$, Hansen AK,Marburg and Ebola virus infection in laboratory non human primates a literature review,Comp Med, 2000; 50(2):108-23.

34. Centres for Disease Control and Prevention. Health advisory network 367: CDC Ebola Response Update \#3. Available at; http://emergency.cdc.gov/han/han00367.asp (Accessed on August 25, 2014).

35. Centres for Disease Control and Prevention. Ebola virus disease information for clinicians in U.S. healthcare settings. Available at; http://www.cdc.gov/vhf/ebolacian-informationus-healthcare-settings.html (Accessed on October 17, 2014).

36. World Health Organisation. Travel and transport risk assessment: Recommendations for public health authorities and transport sector. Available at; http://www.who.int/ith/updates/20140421/en/ (Accessed on August 12, 2014).

37. Peters CJ, Jahrling PB, Khan AS.,Patients infected with highhazard viruses, scientific basis for inection control,Arch Virol Suppl 1996; 11:141-168

38. Bwaka MA, Bonnet MJ, Calain $P$, et al. Ebola hemorrhagic fever in Kikwit, Democratic Republic of the Congo, clinical observations in 103 patients. J Infect Dis., 1999; 179(1):S1-7.

39. Isaacson M, Sureau P,Courteille G, Pattyn SR, Clinical aspects of ebola virus disease at the Ngaliema Hospital, Kinshasa,Zaire in:Ebola virus Haemorrhagic fever, Pattyn S(Ed), Elesevier?North-Holland, Amsterdam 1978, 22.

40. Kortepeter MG, Bausch DG, Bray M. Basic clinical and laboratory features of filoviral hemorrhagic fever.,J Infect Dis., 2011; 204 (3):S810.

41. Formenty $\mathrm{P}$, Hatz $\mathrm{C}$, Le Guenno b, et al,human infection due to ebola virus, subtype cote d'Ivoire; clinical and biologic presentation,J Infect Dis., 1999; 179(1):S48-53.

42. Piot $P, B r e m a n J G, H e y m a m m ~ D L$, et al. Clinical aspects of Ebola virus infection in yambuku area, Zaire, 1976. In Ebola virus Haemorrhage Fever, Pattyn S (Ed),Elsevier?NorthHolland, Amsterdam 1978; 85-97. 
43. Ebola and Marburg viruses: molecular and cellular biology,Horizon Bioscience, 2004.

44. Sanchez, A., Trappier, S. G., Mahy, B. W., Peters, C. J. \& Nichol, S. T.,The virion glycoproteins of Ebola viruses are encoded in two reading frames and are expressed through transcriptional editing, Proc. Natl. Acad. Sci. U. S. A.,1996; 93(8):3602-3607.

45. Hartlieb, B. \& Weissenhorn, W. Filovirus assembly and budding. Virology, 2006; 344(1):64-70.

46. Ramanan, P. et al.,Filoviral immune evasion mechanisms. Viruses, 2011; 3(9):1634-1649.

47. Feldmann, H., Klenk, H. D. \& Sanchez, A., Molecular biology and evolution of filoviruses, Arch. Virol.,1993,7, 81-100.

48. Takada, A. \& Kawaoka, Y.,Antibody-dependent enhancement of viral infection: molecular mechanisms and in vivo implications. Rev. Med. Virol., 2003; 13(6):387-398.

49. Takada, A., Feldmann, H., Ksiazek, T. G. \& Kawaoka, Y., Antibody-dependent enhancement of Ebola virus infection, J. Virol. 2003; 77(13):7539-7544.

50. Kühl, A. \& Pöhlmann, S.,How Ebola virus counters the interferon system.,Zoonoses Public Heal, 2012; 59(2):116131.

51. Ito, H., Watanabe, S., Takada, A. \& Kawaoka, Y., Ebola Virus Glycoprotein: proteolytic processing, acylation, cell tropism, and detection of neutralizing antibodies. J. Virol. 2001; 75(3):1576-1580.

52. Wahl-Jensen, V. M. et al, Effects of Ebola virus glycoproteins on endothelial cell activation and barrier function, J. Virol, 2005; 79(16): 10442-10450.

53. Saeed, M. F., Kolokoltsov, A. A., Albrecht, T. \& Davey, R. A, Cellular entry of ebola virus involves uptake by a macropinocytosis-like mechanism and subsequent trafficking through early and late endosomes. 2010.

54. Watanabe, S., Noda, T., Halfmann, P., Jasenosky, L. \& Kawaoka, Y, Ebola virus (EBOV) VP24 inhibits transcription and replication of the EBOV genome, J. Infect. Dis. 2007; 196(2):S284-290.

55. Timmins, J. et al. Ebola virus matrix protein VP40 interaction with human cellular factors Tsg101 and Nedd4, J. Mol. Biol.2003; 326(2):493-502.
56. Yamayoshi, S. et al. Ebola virus matrix protein VP40 uses the COPII transport system for its intracellular transport. Cell Host Microbe 2008; 3(3):168-77.

57. Kortepeter MG, Bausch DG, Bray M (November 2011). "Basic clinical and laboratory features of filoviral hemorrhagic fever". The Journal of Infectious Diseases, 2011; 204(3):S810-16.

58. Goeijenbier M, van Kampen JJ, Reusken CB, Koopmans MP, van Gorp EC, Ebola virus disease: a review on epidemiology, symptoms, treatment and pathogenesis. The Netherland Journal of Medicine, 2014; 72(9):442-48.

59. "Ebola Hemorrhagic Fever Diagnosis, CDC, 28 March 2016. Available at website. https://www.cdc.gov/vhf/ebola/index.html

60. Grolla A, Lucht A, Dick D, Strong JE, Feldmann H. "Laboratory diagnosis of Ebola and Marburg hemorrhagic fever". Bull Soc Pathol Exot 2005; 98(3):205-9.

61. Geisbert TW, Jahrling PB, Differentiation of Filoviruses by Electron Microscopy, Virus Research, 1995; 39(2-3):129-50.

62. New Ebola Drug Cures Monkeys in Clinical Trail. Available at https://www.telegraph.co.uk/news/worldnews/ebola/11063696 /Ebola-breakthrough-as-new-drug-cures-all-monkeys-intrial.html

63. Ebola Virus: Development of Vaccines and Therapeutic Drugs and Recent Research Reports on Ebola. Available at; https://www.genscript.com/ebola-virus-vaccine-therapeuticdrug-development.html

64. Ebola vaccine trail begins in britain. Available at; https:/in.news.yahoo.com/ebola-vaccine-trail-begins-britain162405851.html

65. "Ebola Hemorrhagic Fever Prevention". (2014) CDC. available at https://www.cdc.gov/vhf/ebola/prevention/index.html

66. Peters J, R Guenael (December). Infection Control for Viral Haemorrhagic Fevers in the African Health Care Setting. World Health Organization, U.S. Department of Health \& Human Services, Public Health Service, Centers for Disease Control and Prevention, 1998, 19-99. 